\title{
TECNOLOGIAS DE INFORMAÇÃO E COMUNICAÇÃO NO ENSINO SUPERIOR: O AMBIENTE VIRTUAL DE APRENDIZAGEM EM CURSO SEMIPRESENCIAL
}

\author{
TECNOLOGÍAS DE INFORMACIÓN Y COMUNICACIÓN EN LA FORMACIÓN \\ A NIVEL SUPERIOR: EL ENTORNO VIRTUAL DE APRENDIZAJE EN UN \\ CURSO SEMIPRESENCIAL
}

INFORMATION AND COMMUNICATION TECHNOLOGIES IN HIGHER EDUCATION: THE VIRTUAL LEARNING ENVIRONMENT IN A BLENDED COURSE

\author{
Dayra Émile Guedes MARTÍNEZ ${ }^{1}$ \\ José Luis BIZELLI ${ }^{2}$ \\ Edson do Carmo INFORSATO ${ }^{3}$
}

RESUMO: O presente artigo analisa a formação em nível superior no Brasil com a utilização de tecnologias de informação e comunicação (TIC) em âmbito legal, apontando iniciativas do estado de São Paulo em projetos educacionais a distância e semipresenciais. Apresentam-se os resultados de uma pesquisa concluída de mestrado sobre a utilização de um ambiente virtual de aprendizagem (AVA) em um curso de Pedagogia semipresencial. A fonte dos dados analisados nesta pesquisa consistiu em questionários aplicados pela instituição responsável pelo curso, a UNESP, aos alunos e tutores. Foram identificados os itens relativos ao AVA e a respostas desses grupos foram analisadas permitindo concluir que ambos, alunos e tutores, tiveram percepções positivas a respeito do ambiente utilizado no curso.

PALAVRAS-CHAVE: TIC no ensino superior. Pedagogia semipresencial. Ambiente virtual de aprendizagem.

RESUMEN: El presente artículo analiza la formación a nivel superior en Brasil con la utilización de tecnologías de información y comunicación (TIC) en ámbito legal, apuntando iniciativas del estado de São Paulo en proyectos educativos a distancia y semipresenciales. Se presentan los resultados de una investigación concluida de maestría sobre la utilización de un entorno virtual de aprendizaje (EVA) en un curso de Pedagogía semipresencial. La fuente de los datos analizados en esta investigación consistió en cuestionarios aplicados por la institución responsable del curso, la UNESP, a los alumnos y tutores. Se identificaron los items relativos al EVA y las

\footnotetext{
${ }^{1}$ Universidade Estadual Paulista (Unesp), Araraquara - SP - Brasil. Mestrado em Educação Escolar. Email: dayraeg@yahoo.com.br.

${ }^{2}$ Universidade Estadual Paulista (Unesp), Araraquara - SP - Brasil. Docente do Programa de Pósgraduação em Educação Escolar. Livre Docente em Gestão de Políticas Públicas. E-mail: bizelli@fclar.unesp.br.

${ }^{3}$ Universidade Estadual Paulista (Unesp), Araraquara - SP - Brasil. Docente do Programa de PósGraduação em Educação Escolar. E-mail: edsontamoio@gmail.com.
} 
respuestas de esos grupos fueron analizadas permitiendo concluir que ambos, alumnos y tutores, tuvieron percepciones positivas respecto al ambiente utilizado en el curso.

PALAVRAS CLAVE: TIC en la enseñanza superior. Pedagogía semipresencial. Entorno virtual de aprendizaje.

ABSTRACT: This article analyzes the training at a higher level in Brazil with the use of information and communication technologies (ICT) in the legal field, pointing out initiatives of the State of São Paulo in distance and semi - distance educational projects. We present the results of a completed master's degree research on the use of a virtual learning environment (VLE) in a blended Pedagogy course. The source of the data analyzed in this research consisted of questionnaires applied by the institution responsible for the course, UNESP, to the students and tutors. The items related to VLE were identified and the responses of these groups were analyzed allowing to conclude that both students and tutors had positive perceptions regarding the environment used in the course.

KEYWORDS: ICT in higher education. Blended learning. Virtual learning environment.

\section{Introdução}

A formação em ensino superior, em todas as áreas, é um aspecto considerado essencial como superação das desigualdades sociais, especialmente no Brasil onde a diferença entre a população mais pobre e a população mais rica é imensa. $O$ contraste nos graus de escolaridade desses dois extremos torna possível estabelecer um vínculo entre o nível de formação e posição social, o que faz com que a igualdade de acesso à educação seja, entre outros aspectos que não cabem neste artigo, determinante rumo a uma sociedade mais democrática.

É importante ressaltar que mesmo o aumento do acesso ao ensino superior não contribui para uma igualdade educacional entre as classes, já que o desempenho do aluno é afetado por diversos fatores, sendo que a baixa renda apresenta uma correlação com baixo desempenho e evasão; dessa forma, a Organização para a Cooperação e Desenvolvimento Econômico (OCDE) (2015) concluiu que mesmo com o aumento do acesso às instituições de ensino superior na América Latina, estas ainda se mantém em um modelo elitista que tende a preservar as desigualdades agora dentro da própria instituição.

Paralelamente, o público menos favorecido pelo ensino convencional, seja pela renda limitada, limite de tempo e disposição geográfica, encontra em instituições não 
tradicionais uma opção para iniciar ou continuar os estudos. O Censo EAD.BR (2016) demonstrou que os cursos a distância atendem, em maioria, alunos na faixa etária entre 31 e 41 anos, e que conciliam o estudo com o trabalho, caracterizando-se como um público que, comumente, não é o perfil do corpo discente de instituições de ensino presencial.

As novas modalidades de ensino provenientes da utilização de TIC no âmbito educacional são uma forma de superar os desafios nos quais se encontram as instituições de ensino superior (IES) na América Latina, a saber: desigualdade de acesso, baixa qualidade, falta de articulação entre as demandas do mercado e o conteúdo desenvolvido nas instituições e, por fim, a pressão internacional que afeta decisões financeiras referentes ao sistema educacional (OCDE, 2015).

Um levantamento realizado pela organização demonstrou que as instituições de ensino superior na América Latina incorporaram, de forma expressiva, tecnologias de informação e comunicação (TIC) como uma forma de melhorar os sistemas de gestão e aumentar a eficiência. A integração de TIC no âmbito administrativo e organizacional representa um avanço da área educacional, possibilitando que as instituições utilizem o potencial dessas tecnologias a seu favor e acompanhem o desenvolvimento das tecnologias, que ocorre, mais intensamente, em outras esferas sociais; como Castells (2008) ressalta, a área da educação utiliza as tecnologias de forma mais branda.

Ainda assim, mudanças nos modelos pedagógicos ainda não são fortemente detectadas com a inclusão de TIC no ensino superior. Iniciativas em educação a distância (EaD), no entanto, ganham força e se expandem no país, podendo ocorrer em modelos mais tradicionais de transmissão de conteúdo ou com propostas diferenciais. Dessa forma, além de promover práticas de ensino que se fundamentam em flexibilidade física e temporal - já que iniciativas educacionais baseadas no uso de TIC liberam o estudante para realizar suas atividades de aprendizagem no local e hora mais adequados às suas particularidades e rotina - também é possível ampliar o campo paradigmático educacional, agregando recursos e procedimentos relativos às novas tecnologias.

A expansão de vagas no ensino superior coloca às instituições o desafio de manter a qualidade da educação e também atualizar, de maneira crítica, o perfil do profissional formado e do conhecimento gerado em relação ao cenário local e global, não apenas para atender demandas momentâneas, ainda que isso seja muitas vezes determinante na prática e auxilie na implantação e continuidade de instituições de 
ensino, já que consiste em um atrativo para investimentos externos e engajamento de estudantes.

Em vista disso, a esfera quantitativa se apresenta como um desafio em relação à estrutura das universidades e ao corpo docente. Concomitantemente, mudanças no âmbito prático e teórico requerem uma reestruturação ideológica na universidade.

Discussões sociais e medidas legais se encaminham para o estabelecimento de uma escola inclusiva, democrática e autônoma que, frente à diversidade, não busca mais a homogeneização, mas a valorização da diferença em todas as suas manifestações. Consequentemente, a postura do professor agora deve ser mais receptiva à heterogeneidade presente em sua sala de aula. Assim, as instituições de ensino superior vêm a necessidade de formar profissionais capazes de lidar com a diversidade de maneira inclusiva, reflexiva e crítica, o que ultrapassa a concepção de docência como transmissão de conhecimentos ou aquisição de comportamentos.

Esta problematização entre o enfoque estrutural-organizacional do uso de TIC no ensino superior e o enfoque didático-pedagógico será apresentada aqui, relacionando medidas legais e iniciativas brasileiras, especificamente do estado de São Paulo, ressaltando o uso de um ambiente virtual de aprendizagem em um curso semipresencial.

\section{Medidas legislativas referentes à utilização de TIC na educação e iniciativas no estado de São Paulo}

Em âmbito legal, o Brasil incentiva a oferta de projetos de ensino experimentais mediados por tecnologias, destacando que essa mediação pode ocorrer dentro da modalidade a distância ou utilizando os recursos e tecnologias dessa modalidade no ensino presencial (BRASIL, 1996).

O Plano Nacional de Educação (BRASIL, 2001) já compreendia que a EaD apresenta um grande potencial para sanar as deficiências do sistema educacional convencional. Destaca-se, como inserido na legislação, que a inserção de tecnologias na educação influem na tomada de decisões, tanto pelos profissionais quanto pela comunidade escolar. Além disso, o plano destaca o potencial da EaD em expandir o acesso à educação e à formação de qualidade.

Pensar a EaD como um simples apoio para a educação tradicional, no entanto, é uma forma reducionista de compreender as potencialidades dessa modalidade, e também leva à sua desvalorização em relação ao ensino presencial, mantendo uma 
polarização generalista já recorrente na qual a educação na modalidade a distância é ruim e a educação presencial é boa. Nessa concepção, também o uso de TIC no processo educacional é banalizado. Ainda que seja possível ensinar de forma colaborativa, flexível e em forma de rede com tecnologias não digitais, essas potencializam a experiência educacional e a aprendizagem dentro de abordagens inovadoras, já que permitem práticas pedagógicas antes impensadas por conta das limitações tecnológicas.

$\mathrm{O}$ artigo 80 da Lei de Diretrizes e Bases foi regulamentado pelo Decreto $\mathrm{N}^{\circ}$ 5.622, de 19 de dezembro de 2005 (BRASIL, 2005), recentemente revogado pelo Decreto No 9.057, de 25 de maio de 2017 (BRASIL, 2017). Destaca-se, aqui, dentre as modificações ocorridas, a definição de EaD, primeiramente compreendida como:

[...] modalidade educacional na qual a mediação didático-pedagógica nos processos de ensino e aprendizagem ocorre com a utilização de meios e tecnologias de informação e comunicação, com estudantes e professores desenvolvendo atividades educativas em lugares ou tempos diversos (BRASIL, 2005).

Com o novo decreto, a modalidade passa a ser definida da seguinte forma:

[...] modalidade educacional na qual a mediação didático-pedagógica nos processos de ensino e aprendizagem ocorra com a utilização de meios e tecnologias de informação e comunicação, com pessoal qualificado, com políticas de acesso, com acompanhamento e avaliação compatíveis, entre outros, e desenvolva atividades educativas por estudantes e profissionais da educação que estejam em lugares e tempos diversos (BRASIL, 2017, grifo nosso).

Percebe-se que a redação não foi profundamente modificada, apesar do trecho inserido em destaque, que evidencia a necessidade de sistemas específicos de acesso, acompanhamento e avaliação e profissionais qualificados para atuar na modalidade. Além disso, outros aspectos não descritos, mas que são abarcados em “entre outros", que podem se referir a aspectos pedagógicos, estruturais, tecnológicos e financeiros, são considerados no novo decreto.

Apesar da mediação tecnológica e da separação geográfica serem fatores determinantes para a conceituação da área, não é possível identificar a abordagem pedagógica vigente baseando-se nesses dois fatores. Moore e Kearsley (2008) ressaltam a importância de considerar as implicações da separação geográfica e temporal na 
dinâmica do processo ensino e aprendizagem em todos os âmbitos, desde o planejamento à avaliação.

Mill (2016) ressalta a abundância de termos utilizados corriqueiramente como sinônimos, mas que se referem a projetos educacionais com diferenças tecnológicas, pedagógicas e metodológicas essenciais.

A articulação de recursos e tecnologias da $\mathrm{EaD}$ com o ensino in loco pode ocorrer em várias intensidades, sendo o ensino semipresencial uma dessas possibilidades. Comumente, entende-se como semipresencial projetos educacionais que mesclem a prática do ensino presencial com a $\mathrm{EaD}$, distribuindo a carga horária total em $40 \%$ de atividades presenciais e $60 \%$ a distância. Nessa abordagem, ambas as práticas de ensino parecem ser bastante consolidadas pedagógica e metodologicamente, sendo que não há mudanças significativas em nenhuma das partes.

As instituições de ensino superior têm respaldo legal para ofertar parte de suas disciplinas nessa abordagem, conforme a seguinte definição de semipresencial:

[...] quaisquer atividades didáticas, módulos ou unidades de ensinoaprendizagem centrados na auto-aprendizagem e com a mediação de recursos didáticos organizados em diferentes suportes de informação que utilizem tecnologias de comunicação remota (BRASIL, 2004)

Além de considerar a utilização de TIC e a separação geográfica, o trecho acima apresenta como requisito essencial na abordagem semipresencial a autoaprendizagem.

De outro modo, a articulação de tecnologias de ensino a distância e in loco pode ocorrer com a profunda modificação em ambos os momentos, em projetos educacionais elaborados especificamente a um contexto particular, considerando suas peculiaridades, surgindo práticas únicas e inovadoras.

Os recursos e tecnologias utilizados no ensino, então, tanto em EaD quanto no semipresencial, podem se aproximar de abordagens mais tradicionais e conteudistas ou mais inovadoras e centradas no aluno. Nesse contexto, analisa-se a utilização de um ambiente virtual de aprendizagem (AVA), prática já incorporada na EaD online e que vem ganhando espaço com a aproximação com o ensino presencial e, principalmente, em contexto semipresencial:

Com base nas estratégias de ensino a distância, o ambiente virtual de aprendizagem disponibiliza ferramentas que favorecem o aprendizado 
e o acesso às informações, fomentando a troca de experiências e permitindo que o aluno seja agente do seu próprio conhecimento (AHAD, 2016, p. 52.)

A elaboração de um AVA, ou a escolha por um já existente, depende de vários fatores que perpassam o âmbito financeiro e pedagógico. Cada ambiente é desenvolvido com uma abordagem pedagógica orientadora. Ainda que a customização pelos utilizadores garanta uma maior flexibilidade em relação a esse aspecto, um ambiente concebido em determinada ideologia será utilizado com maior potencial se a instituição, ou curso ou docente, também se inserirem dentro da mesma ideologia.

O MOODLE, por exemplo, plataforma utilizada pelo sistema Universidade Aberta do Brasil (UAB), foi concebido dentro de uma abordagem socioconstrutivista ${ }^{4}$; já o TelEduc foi desenvolvido em uma abordagem construcionista contextualizada (ROCHA, 2002). Comumente, AVA têm um sistema de gestão de aprendizagem (SGA) que permitem organizar, acompanhar e avaliar o processo de aprendizagem através de ferramentas de disponibilização de recursos e monitoramento de atividades realizadas no ambiente (como trabalhos e também interações e discussões) (BIZELLI, 2013).

Somadas à versatilidade temporal e geográfica, propostas de ensino ainda mais flexíveis permitem a convergência de diferentes ritmos de aprendizagem em um ambiente com objetivos semelhantes e conteúdos e metodologias variadas e condizentes com a realidade, necessidade e interesses do público atendido. Além do que, essas práticas promovem uma “otimização do saber científico" (LEMES, 2007, p. 83), no sentido de disponibilizar mais facilmente conteúdos antes presentes somente nos campi das instituições, como livros que agora se encontram em formato digital para o acesso dos alunos.

Nesse contexto, a UNESP realiza ações condizentes com a expansão do ensino superior, dentro da nova perspectiva pedagógica e da legislação pertinente. O Pedagogia Cidadã foi um curso oferecido em parceria com as prefeituras do estado de São Paulo, implantado em outubro de 2002, para a formação de professores em exercício sem formação superior em Pedagogia.

Esse programa ofereceu, de 2002 a 2007, cursos de graduação de dois anos em Pedagogia aos professores de educação infantil e das séries iniciais do ensino fundamental que tinham apenas o diploma de ensino médio. A carga horária total (3390

\footnotetext{
4 “Filosofia do Moodle”. Disponível em: < https://docs.moodle.org/all/pt_br/Filosofia_do_Moodle>.
} Acesso em 13 out. 2016. 
horas) foi distribuída em encontros presenciais diários com os tutores do curso em espaços definidos pelas prefeituras e, duas vezes por semana, em videoconferências com professores da UNESP e outras instituições.

Essa experiência pode evidenciar que a formação tradicional nas IES é limitadora em relação à capacidade de disponibilização do conhecimento com as tecnologias atuais, e reduz a formação em nível superior a um contingente reduzido de pessoas:

[...] a socialização do conhecimento e da informação ganha espaço cada dia e esta socialização se dá por meio da instrumentação eletrônica enquanto que as salas de aula tradicionais já começam a evidenciar os seus laços com as referências do passado ou a reforçar modalidades de processos formativos para os quais a abrangência e a inclusão são direcionadas para a formação de poucos (LEMES, 2007, p. 93).

Com a instituição do Núcleo de Educação a Distância (NEaD) (RESOLUÇÃO UNESP N47, 2008), responsável pelos aspectos relativos ao material didático, atuação dos profissionais na área, serviços acadêmicos e serviços técnicos, a UNESP pode intensificar as iniciativas relativas a EaD. Atualmente, o núcleo desenvolve uma ferramenta para auxiliar os docentes da universidade a criar cursos online como um suporte à prática presencial de ensino, ou online, em uma perspectiva de educação híbrida (SCHLÜNZEN JUNIOR, 2016).

Outra iniciativa da instituição é a UNESP Aberta ${ }^{5}$, que, ao seguir os avanços mundiais da modalidade a distância, oferece cursos abertos e livres (MOOCs), disponibilizando conteúdos e materiais didáticos dos cursos da universidade, elaborados em colaboração com o NEaD; para tanto, é utilizado um AVA na plataforma Moodle (SCHLÜNZEN JUNIOR, 2016).

Já em âmbito estadual, destaca-se o Programa Universidade Virtual do Estado de São Paulo - UNIVESP - que foi instituído através do Decreto No 53.536, de 9 de outubro de 2008, com o objetivo de expandir o ensino superior público de qualidade no estado de São Paulo com a utilização de TIC (SÃO PAULO, 2008, s/p.). Para tanto, estabeleceu-se parceria com três universidades públicas (USP, UNICAMP e UNESP), com o Centro Estadual de Ensino Tecnológico Paula Souza e a Fundação Padre Anchieta (VOGT, 2013).

${ }^{5}$ Disponível em: <https://unespaberta.ead.unesp.br/>. Acesso em 28 fev. 2017. 
Uma realização relevante da fundação é a UNIVESP TV, que se propõe a transmitir e criar conteúdo específico como suporte para os cursos da UNIVESP e, dentro da perspectiva do conhecimento como bem público, para toda a comunidade ${ }^{6}$. Os vídeos estão disponíveis gratuitamente no canal da TV no YouTube, criado em 26 de abril de 2010; em 2013, a plataforma possuía cerca de 11,6 milhões de visualizações em seus conteúdos e aproximadamente 66 mil inscritos (VOGT, 2013). Atualmente, o canal tem mais de 55 milhões de visualizações e mais de 327 mil inscritos ${ }^{7}$.

Nesse contexto de expansão do acesso às universidades públicas com uso de TIC, e a demanda de formação de professores, é que a UNESP realiza uma parceria com a UNIVESP para a oferta de um curso de pedagogia aos professores em exercício do estado.

O curso de Pedagogia UNESP/UNIVESP: Programa de Formação de Professores em Exercício no Estado de São Paulo, para a Educação Infantil, para as Séries Iniciais do Ensino Fundamental e para a Gestão de Unidade Escolar, foi criado em 2009 e motivado por decisões legais que compreendem a descentralização e autonomia das escolas e seus profissionais, em busca de flexibilidade e criatividade.

Para que as tecnologias tenham maior aproveitamento de suas potencialidades e para que o processo de ensino seja coerente com as demandas de aprendizagem, seu uso tem que perpassar a formação de professores, de modo que estes desenvolvam maior desenvoltura para utilizar as ferramentas tecnológicas e o façam de acordo com abordagens pedagógicas modernas e condizentes com o contexto - objetivos, alunos, infraestrutura e outras variáveis - no qual se inserem.

O programa de formação de professores em questão foi orientado por dois princípios: “[...] oferecer novas possibilidades de organização para programas de formação de professores e explorar os recursos tecnológicos de comunicação e informação reconhecendo as possibilidades existentes para ações educacionais" (MENIN et al., 2010, p. 13).

O curso foi oferecido pela UNESP em parceria com a Universidade Virtual do Estado de São Paulo (UNIVESP). O período letivo do curso se iniciou em $1^{\circ}$ de março de 2010. Com duração de três anos e meio (sete semestres), a carga horária mínima era de 3480 horas, das quais $40 \%$ foram realizadas em atividades presenciais, e as outras

\footnotetext{
6 "Sobre a UNIVESP TV". Disponível em: <http://univesptv.cmais.com.br/sobre-a-univesptv>. Acesso em 22 fev. 2017.

7 “Sobre”. Disponível em: <https://www.youtube.com/user/univesptv/about>. Acesso em 22 fev. 2017.
} 
$60 \%$ em atividades a distância. Foram disponibilizadas 1350 vagas distribuídas em 21 cidades com polos de educação a distância da UNESP. Vale ressaltar o impacto que esse curso gerou no panorama geral do estado em relação aos cursos de Pedagogia:

As 1350 vagas oferecidas para o curso de Pedagogia no ano de 2010 configuraram um aumento de $21 \%$ do total de vagas de graduação da Unesp, passando de 6.865 para 8.215. Se considerado o número total das três universidades públicas de São Paulo, o aumento nas vagas de graduação foi de $6,5 \%$. Por fim, a oferta do curso pela Univesp quase triplicou o número de vagas na soma da oferta das três universidades estaduais paulistas em Pedagogia, passando-se de 745 para 2095 vagas (VOGT, 2013, 86).

Esse aumento quantitativo vem de encontro à demanda de mais profissionais com formação adequada em nível superior para atuar nas escolas. A primeira turma formou, em 2013, 992 professores.

O Manual do Aluno (DEBIEUX; MARANHE; FEITOSA, 2010) destaca que o aluno irá proceder no curso de modo diferente do que na educação presencial tradicional, sendo o principal responsável pela sua aprendizagem. O material indica que o aluno deve ter um posicionamento ativo e autônomo, agindo de forma reflexiva sobre seu próprio ritmo e estilo de aprendizagem enquanto também considera o grupo, equilibrando os aspectos individuais e coletivos na construção do conhecimento para que possa alcançar sucesso em seu processo de aprendizagem.

O curso contou com três recursos principais: AVA UNESP - foi utilizado na primeira edição do curso; o TelEduc, e vídeos e material impresso; também contava com três tipos de docentes que exerciam atividades específicas ao longo do curso: professores autores que eram responsáveis pela elaboração do curso, orientadores de disciplina (ODs) e orientadores de turma (OTs), ambos encarregados de acompanhar os alunos ao longo do processo (MENIN et al., 2010).

Em 2015, a UNESP novamente abriu vagas para o curso de Pedagogia semipresencial para professores em exercício, desta vez, realizando parceria com a CAPES, no sistema UAB, e a Prefeitura Municipal de São Paulo.

A parceria com a prefeitura de São Paulo ocorre dentro do projeto "A Universidade no CEU", que pretende levar o ensino superior gratuito às unidades dos Centros Educacionais Unificados (CEUs). Para atender a demanda pelo curso, a prefeitura disponibilizou 18 unidades do CEU como polos de atividades presenciais realizadas duas vezes por semana. A duração de 40 meses, a divisão da carga horária, 
$60 \%$ a distância e $40 \%$ presencial, e os três requisitos apresentados anteriormente a serem atendidos pelos interessados se mantiveram; no entanto, houve uma diminuição no número de vagas ofertadas: de 1350 vagas em 2009 para 900 vagas em 2015.

\section{Análise de dados e discussão}

A fonte dos dados analisados na pesquisa de mestrado concluída consiste em questionários aplicados pela UNESP aos alunos e tutores do curso de Pedagogia semipresencial da instituição, aplicados em maio de 2013, ou seja, à primeira turma formada pelo curso, com o objetivo de melhoria e institucionalização do mesmo. $\mathrm{O}$ questionário foi aplicado presencialmente em formato impresso.

As questões que compuseram os questionários avaliativos relativos aos aspectos do curso foram estruturadas em uma escala de medição de atitudes, a saber, Escala Likert, que vai de 0 (zero) a 6 (seis), onde 6 equivale a sim completamente e 0 equivale a não totalmente ${ }^{8}$. As respostas aos questionários foram averiguadas através dos Relatórios Finais de outubro de 2013. Para a elaboração dos relatórios, as questões de cada parte foram agrupadas de acordo com o assunto. Foram identificados, nos questionários, os itens relativos ao AVA.

A seguir, apresentam-se os questionários aplicados por público participante, alunos, ODs e OTs, em conformidade com as particularidades de cada questionário e destacando os tópicos referentes ao AVA, que é o tema central desta pesquisa.

Do questionário dos alunos, destacam-se as seguintes questões:

41. A utilização da plataforma foi realizada de forma simples e compatível com as atividades de ensino e com os conhecimentos tecnológicos dos alunos?

42. As ferramentas da plataforma, utilizadas nas diferentes disciplinas, foram suficientes e adequadas aos seus objetivos e conteúdos?

O relatório final dos alunos foi aglomerado em polos e as respostas foram analisadas pelo agrupamento; dessa forma, não é possível verificar as respostas a cada pergunta, e sim as repostas de acordo com o conjunto temático. No caso, o conjunto sobre infraestrutura, que incluiu, além das questões 41 e 42 acima mencionadas, as questões 43, 44 e 45:

\footnotetext{
${ }^{8} \mathrm{O}$ formato do questionário original elaborado pela UNESP - a redação dos itens levantados e a escala de
} 0 a 6 - foi mantido para a análise de dados na pesquisa realizada. 
43. Os recursos materiais (computadores, sala de aula, material didático), disponíveis no Polo, atenderam às suas necessidades?

44. As instalações disponibilizadas para as aulas presenciais e para a implantação do laboratório de informática são adequadas?

45. O uso do laboratório de informática foi adequado às atividades do curso e os equipamentos estiveram disponíveis sempre que necessário?

Como a quantidade de alunos foi muito maior que a de orientadores, isso pode ter motivado a realização do relatório dessa forma.

O Gráfico 1 demonstra os conceitos atribuídos pelos alunos a esse conjunto de itens. O gráfico apresenta que a maioria dos estudantes teve percepções ${ }^{9}$ positivas sobre a infraestrutura do curso, em relação à plataforma e aos polos presenciais, ainda que conceitos neutros e negativos tenham sido atribuídos ao quesito infraestrutura, e mesmo com algumas questões que foram deixadas em branco.

Do questionário dos orientadores de disciplina, destaca-se as seguintes questões:

1. A utilização da plataforma foi realizada de forma simples e compatível com as atividades de ensino e com os conhecimentos tecnológicos dos alunos?

2. As ferramentas da plataforma, utilizadas nas diferentes disciplinas, foram suficientes e adequadas aos seus objetivos e conteúdos?

3. Os conteúdos disponibilizados na plataforma foram suficientes e adequados aos objetivos das disciplinas e compatíveis com a formação do pedagogo?

4. As ferramentas da plataforma foram exploradas em todo seu potencial, possibilitando uma boa interatividade entre os usuários?

5. Quando necessário, o suporte da Equipe Técnica para o funcionamento da plataforma foi rápido e eficiente?

Gráfico 1: Gráfico obtido das respostas dadas pelos alunos ao conjunto de itens sobre infraestrutura.

\footnotetext{
${ }^{9}$ Aqui, entende-se por percepção a manifestação opinativa dos grupos participantes, alunos e tutores, frente ao questionário aplicado.
} 


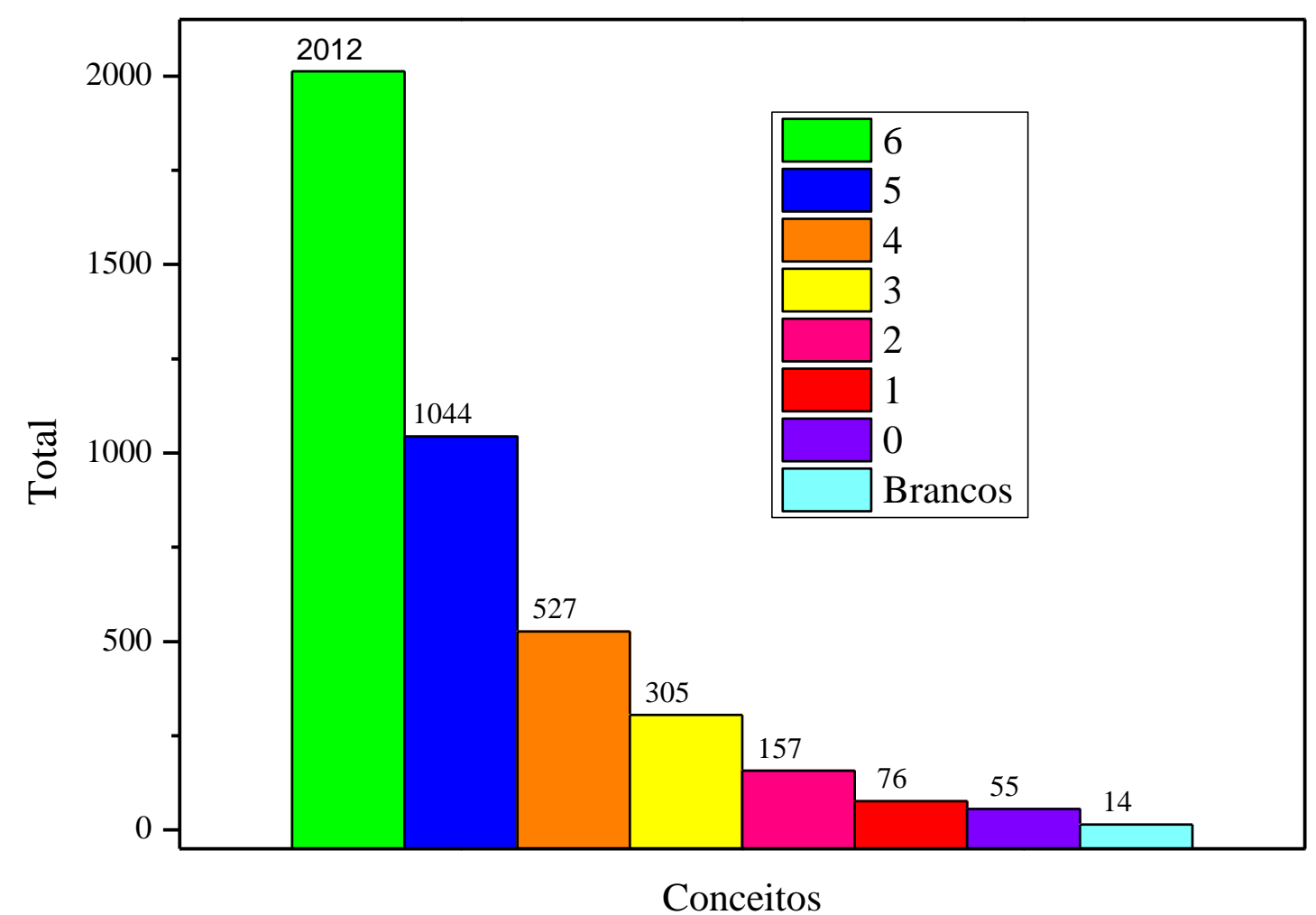

Fonte: Elaboração própria.

Diferentemente do relatório de respostas dos alunos, as respostas dos orientadores de disciplina é descrita por questão, sendo possível analisar as respostas a cada item separadamente, como apresentado a seguir no Gráfico 2.

Logo, a partir do Gráfico 2, percebe-se que a maioria dos ODs atribuiu conceitos máximos, 6 e 5, a todas as questões, revelando um posicionamento bastante positivo em relação ao uso do AVA, suas ferramentas, o conteúdo disponibilizado na plataforma e a assistência técnica oferecida. As questões 1, 2, 3 e 5 apresentam a grande maioria de respostas com conceito 6 , seguidas pelo conceito 5 .

Já a questão 4, que indagou sobre o aproveitamento do potencial das ferramentas do AVA e sobre a interação entre os usuários, se destaca por apresentar a maioria de respostas com conceito 5, seguidas pelo conceito 4. Embora o conceito 6 venha em seguida, as respostas com conceito 3 se aproximam. A essa questão também foram atribuídos conceitos menores, 2 e 1. 
Gráfico 2: Gráfico obtido das respostas dadas pelos ODs a cada questão.

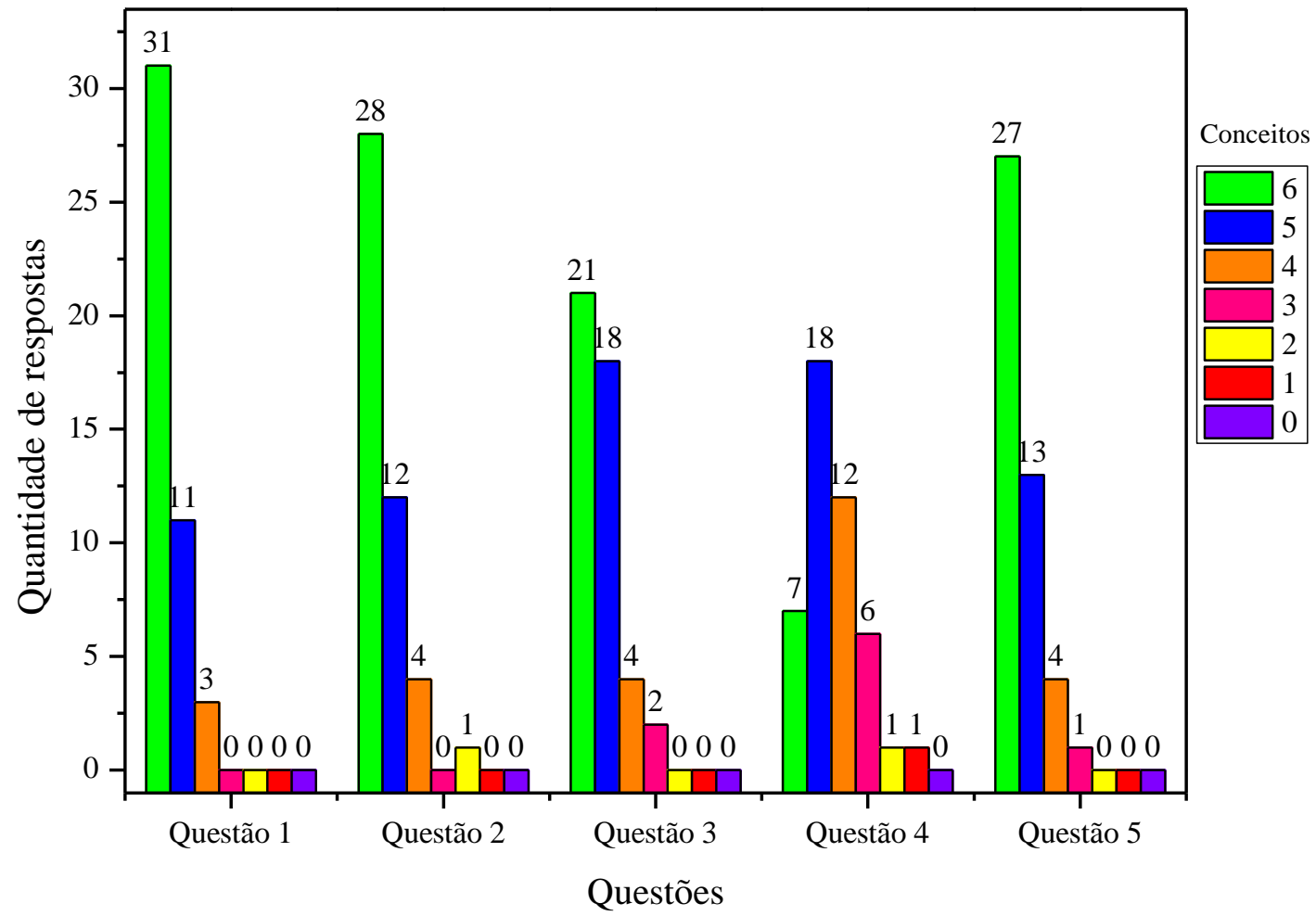

Fonte: Elaboração própria.

Ainda que a maioria das respostas à questão 4 tenha sido positiva, o deslocamento da prevalência dos tutores dos conceitos máximos e positivos para os conceitos centrais e neutros pode revelar que, embora considerem que o AVA, suas ferramentas e conteúdos, tenham sido utilizados em conformidade com os objetivos do curso e com a formação profissional pretendida, a interatividade entre os usuários na plataforma ainda não atingiu um grau que o grupo de tutores, como um todo, considerasse excelente. Ademais, a questão se referiu à exploração de todo o potencial das ferramentas da plataforma, o que revela que as ferramentas não foram aproveitadas em todas as suas potencialidades.

De modo geral, a avaliação que os ODs realizaram sobre o AVA demonstrou que o uso da plataforma, assim como os conteúdos nela disponibilizados, ocorreu dentro dos princípios metodológicos e pedagógicos do curso, de forma simples, considerando o conhecimento tecnológico dos envolvidos, e com assistência técnica ágil e competente.

O questionário aplicado aos orientadores de turma conteve, em sua maioria, as mesmas questões que o questionário dos orientadores de disciplina, ou seja, os itens 
identificados correspondem aos apresentados anteriormente no questionário dos orientadores de disciplina. Além desses, foi destacada também a seguinte questão:

15. A plataforma foi ferramenta importante para suas atividades de orientação do TCC e do estágio supervisionado?

Em seguida, o Gráfico 3 apresenta as respostas dadas pelos OTs a essas questões.

Gráfico 3: Gráfico obtido das respostas dadas pelos OTs a cada questão.

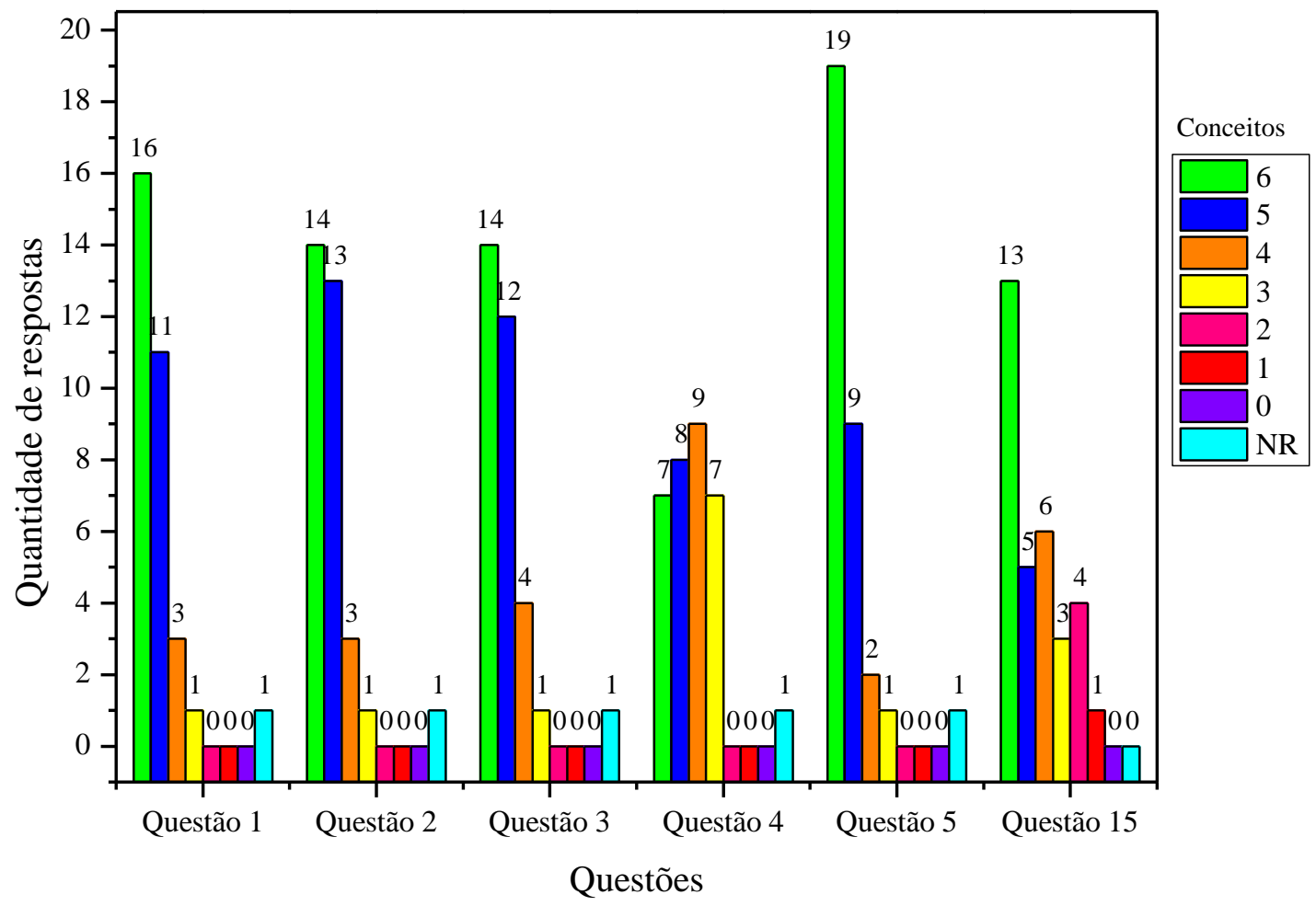

Fonte: Elaboração própria.

Como observado no Gráfico 3, a questão 4 apresenta um maior equilíbrio de respostas: não houve um conceito que se destacasse, sendo que as respostas variaram entre uma percepção neutra a uma positiva. A questão 15, apesar de ter uma maioria de respostas com conceito positivo, também demostra uma parte de percepções neutras sobre o uso da plataforma para orientações de estágio e TCC. Assim como os ODs, a avaliação dos OTs sobre o AVA e sua utilização foi, de modo geral, bastante positiva.

A questão número 4, sobre o potencial do AVA e a interatividade, levantou alguns questionamentos sobre os aspectos considerados pelos tutores ao atribuírem os conceitos. 
Pode-se indagar quais aspectos da plataforma foram identificados pelos tutores e não foram explorados ao longo do curso, resultando em uma percepção satisfatória desses grupos - e não excelente - em relação ao potencial do AVA e a interação entre os usuários. Em contrapartida, questiona-se se o parâmetro ponderado para responder a essa questão foi a interação em sala de aula, e se essa prática enraizada ainda é considerada como ideal em comparação a outros programas educacionais com diferentes abordagens.

Os dois pontos presentes na questão, potencial do AVA e interatividade entre usuários, suscita indagar também a correspondência entre eles, especulando-se se existe uma relação de causa e efeito: se o potencial do AVA for totalmente aproveitado significa que haverá mais interatividade; ou se, no caso, não é possível estabelecer uma relação linear simples considerando que os alunos podem se mobilizar independentemente da plataforma e estabelecer outros canais de comunicação, utilizando o AVA somente para realizar as atividades obrigatórias.

\section{Considerações finais}

A emergência de novas tecnologias possibilita e motiva alterações na dinâmica social, perpassando os mais diversos âmbitos, desde o cultural até o econômico. Além disso, o desenvolvimento e utilização de novas tecnologias modifica, de maneira profunda, a relação do ser humano com o conhecimento.

Mesmo com as inúmeras mudanças observadas, as instituições de ensino tradicionais encontram dificuldades, e até resistência, em modificar sua estrutura em conformidade com os novos princípios sociais e tecnológicos. Ainda que TIC adentrem o espaço escolar nas áreas administrativas e de gestão, as mudanças ocorrem em menor dimensão nos âmbitos pedagógicos e metodológicos.

Ainda assim, surgem experiências educacionais que consideram esses novos paradigmas e utilizam as tecnologias como meio principal, ou auxiliar, para o processo de aprendizagem, como cursos e disciplinas a distância e semipresenciais.

A polarização recorrente entre ensino presencial e a distância fica mais diluída conforme ambas as áreas se entrelaçam no desenvolvimento de práticas variadas e a conceituação de suas características principais ultrapassa os contextos geográficos e temporais. A definição no campo parece não ter contornos claros e estáticos, mas 
desloca sua órbita em nós conceituais diversos, por vezes se aproximando de uma abordagem mais objetiva e tradicional ou buscando perspectivas inovadoras.

Com isso, ressaltamos a possibilidade de ampliação do campo educacional de modo a atender diferentes necessidades, com propostas de ensino flexíveis e abertas, que não sejam consideradas inferiores, e que disseminem a formação de qualidade e significativa a um número cada vez maior e a uma maior variedade de pessoas. Programas desse tipo expandem a formação em nível superior com a utilização intensiva de TIC.

Um aspecto essencial desses cursos é a utilização de AVA. As respostas dos questionários aqui analisados revelaram que alunos e tutores tiveram uma percepção positiva a respeito do ambiente utilizado no curso de Pedagogia semipresencial. No entanto, os tutores apontaram que as potencialidades da plataforma não foram totalmente aproveitadas e que a interatividade entre os usuários na plataforma ainda não atingiu um grau que o grupo de tutores considerasse excelente. Além disso, os OTs apresentaram percepções neutras sobre o uso da plataforma para orientação de estágio e TCC.

A problematização desses aspectos se encontra em um campo ainda maior que se refere aos indicadores considerados ao avaliar e ofertar um curso a distância ou semipresencial. Os valores que orientam a prática tradicional de ensino são insuficientemente transpostos à $\mathrm{EaD}$, por conta das modificações no processo educacional que a modalidade prevê, o que demanda a organização de novos critérios avaliativos.

Mesmo com uma longa trajetória, a instituição da EaD ainda é nova, se considerada a tradição milenar de ensino face-a-face, o que gera uma tendência de retorno aos parâmetros convencionais de ensino e de aprendizagem, tão enraizados que são considerados ideais, para abordar um programa na modalidade; uma prática compreensível, já que a singularidade e diversidade da área tendem a gerar instabilidade e incertezas. Articular o padrão de qualidade de uma instituição de ensino com um processo educacional descentralizado, aberto, distribuído e flexível consiste em um desafio que pode recair no monitoramento e controle do processo de aprendizagem, o que pode gerar inconsistências metodológicas.

Essas inquietações, no entanto, não são exclusivas das instituições de ensino e dos docentes. Esse novo contexto exige uma postura ativa, crítica e autônoma dos estudantes, que também podem se sentir desorientados, desmotivados e insatisfeitos, já 
que foram formados dentro de outra perspectiva. Sendo assim, algumas ferramentas e técnicas tradicionais, que muitas vezes contradizem as teorias e pesquisas mais inovadoras, se fazem necessárias para que os estudantes possam desenvolver essas habilidades e não abandonar o curso ou disciplina antes de terem a chance de se familiarizar com outras abordagens. Ao elucidar esses pontos, seria possível constatar o valor das atividades realizadas na plataforma no processo de aprendizagem e identificar práticas essenciais para que o uso de um AVA não ocorra apenas como resposta a um requisito institucional e/ou como preenchimento de carga horária.

Agradecimentos: À CAPES pela concessão de bolsa.

\section{REFERÊNCIAS}

AHAD, A. M. A. Tecnologias de informação e comunicação como estratégia pedagógica para a educação. In.: NEVES, I. de S. V.; CORRADI, W.; CASTRO, C. L. F. de (orgs.). EaD: diálogo, compartilhamentos, práticas e saberes. Barbacena: EdUEMG, 2016. P. 47-56.

BIZELLI, J. L. Inovação: limites e possibilidades para aprender na era do conhecimento. São Paulo: Cultura Acadêmica, 2013. 195p.

BRASIL. Decreto $\mathbf{N}^{\circ} \mathbf{5 . 6 2 2}$ de 19 de dezembro de 2005. Regulamenta o Art. 80 da Lei n 9.394, de 20 de dezembro de 1996, que estabelece as diretrizes e bases da educação nacional. Disponível em: <http://www.planalto.gov.br/ccivil_03/_Ato20042006/2005/Decreto/D5622.htm>. Acesso em: 21 ago. 2015.

BRASIL. Decreto No 9.057 de 25 de maio de 2017. Regulamenta o art. 80 da Lei ${ }^{\circ}$ 9.394, de 20 de dezembro de 1996, que estabelece as diretrizes e bases da educação nacional. Disponível em: <http://www.planalto.gov.br/ccivil_03/_Ato20152018/2017/Decreto/D9057.htm>. Acesso em: 23 jun. 2017.

BRASIL. Lei $\mathbf{N}^{\circ} \mathbf{9 . 3 9 4}$ de 20 de dezembro de 1996. Estabelece as diretrizes e bases da educação nacional. Disponível em:

<http://www.planalto.gov.br/ccivil_03/leis/19394.htm>. Acesso em: 21 ago. 2015.

BRASIL. Lei $\mathbf{N}^{\circ} \mathbf{1 0 . 1 7 2}$ de 9 de janeiro de 2001. Aprova o Plano Nacional de Educação e dá outras providências. Disponível em:

<http://portal.mec.gov.br/arquivos/pdf/L10172.pdf>. Acesso em: 06 jul. 2017.

BRASIL. Portaria No 4.059 de 10 de dezembro de 2004. Disponível em:

<http://portal.mec.gov.br/sesu/arquivos/pdf/nova/acs_portaria4059.pdf〉. Acesso em 13 set. 2016.

Censo EAD.BR: Relatório Analítico da Aprendizagem a Distância no Brasil $2015=$ Censo EAD.BR: Analytic Report of Distance Learning in Brazil 2015/[organização] 
ABED - Associação Brasileira de Educação a Distância; [traduzido por Maria Thereza Moss de Abreu]. Edição bilíngue: português/inglês. Curitiba: InterSaberes, 2016. Disponível em: 〈http://abed.org.br/arquivos/Censo_EAD_2015_POR.pdf〉. Acesso em: 17 nov. 2016.

DEBIEUX, M.; MARANHE, E. A.; FEITOSA, D. F. Manual do Aluno (Programa de Formação de Professores em Exercício, para Educação Infantil, para Séries Iniciais do Ensino Fundamental e para Gestão da Unidade Escolar). São Paulo: Cultura Acadêmica Editora, 2010.

LEMES, S. de S. Considerações acerca da estrutura e metodologia do Pedagogia Cidadã. In.: FILHO, J. C. P. (org.). Pedagogia Cidadã: uma nova prática na formação do educador. São Paulo: UNESP, Pró-Reitoria de Graduação/ Rettec Artes Gráficas, p. 81-86, 2007.

MENIN, A. M. da C. S. et al. Manual Acadêmico do Curso de Pedagogia (Programa de Formação de Professores em Exercício, para Educação Infantil, para Séries Iniciais do Ensino Fundamental e para Gestão da Unidade Escolar). São Paulo: Cultura Acadêmica Editora, 2010.

MILL, D. Gestão estratégica da educação a distância: constituição, complexidades e desafios. In.: NEVES, I. de S. V.; CORRADI, W.; CASTRO, C. L. F. de (orgs.). BRANCO, J. C. S. (coord.). EaD: diálogos, compartilhamentos, práticas e saberes. Barbacena: EdUEMG, p. 129-144. 2016.

MOORE, M. G.; KEARSLEY, G. Educação a distância: uma visão integrada. Tradução de Roberto Galman. São Paulo: Cengage Learning, 2008. 398p.

OECD (Organization for Economic Co-operation and Development). E-Learning in Higher Education in Latin America. Paris: Development Centre Studies/OECD Publishing, 2015. Disponível em: <http://dx.doi.org/10.1787/9789264209992-en>. Acesso em: 12 set. 2016.

ROCHA, H. V. da. O ambiente TelEduc para educação a distância baseada na web: princípios, funcionalidades e perspectivas de desenvolvimento. In: MORAES, M. C. (org.). Educação a distância: fundamentos e práticas. Campinas: UNICAMP/NIED, p. 197-204, 2002. Disponível em:

<http://www.teleduc.org.br/sites/default/files/publications/8_Cap11_heloisa.pdf >. Acesso em: 14 out. 2016.

SCHLÜNZEN JUNIOR, K. O Núcleo de Educação a Distância da UNESP. Journal of Research in Special Educational Needs, v. 16, p. 770-773, 2016. Disponível em: <http://onlinelibrary.wiley.com/doi/10.1111/1471-3802.12215/full>. Acesso em: 28 fev. 2017.

VOGT, C. A. Universidade Virtual do Estado de São Paulo: breve histórico e perspectivas futuras. Muitas Vozes, Ponta Grossa, v. 2, n 1, p. 85-92, 2013. Disponível em:

<http://www.revistas2.uepg.br/index.php/muitasvozes/article/view/5978/pdf_96>. Acesso em: 22 fev. 2017. 


\section{Como referenciar este artigo}

MARTÍNEZ, Dayra Émile Guedes.; BIZELLI, José Luis.; INFORSATO, Edson do Carmo. Tecnologias de informação e comunicação no ensino superior: o ambiente virtual de aprendizagem em curso semipresencial. Revista Ibero-Americana de Estudos em Educação, Araraquara, v. 12, n. esp. 2, p. 1349-1371, ago./2017. Disponível em: <http://dx.doi.org/10.21723/riaee.v12.n.esp.2.10302>. E-ISSN: 19825587.

Submetido em: 10/04/2017

Aprovação final em: 28/07/2017 